\title{
Hemolytic Uremic Syndrome in Pediatric Intensive Care Units in São Paulo, Brazil
}

\author{
Renato Lopes de Souza ${ }^{1}$, João Tomás Abreu Carvalhaes ${ }^{2}$, Lucilia Sanae Nishimura ${ }^{3}$, \\ Maria Cristina de Andrade ${ }^{2}$ and Beatriz Ernestina Cabilio Guth ${ }^{3, *}$ \\ ${ }^{I}$ Pediatric Intensive Care Unit, Department of Pediatrics, Universidade Federal de São Paulo, São Paulo, Brazil \\ ${ }^{2}$ Nefrology Section, Department of Pediatrics, Universidade Federal de São Paulo, São Paulo, Brazil \\ ${ }^{3}$ Department of Microbiology, Immunology and Parasitology, Universidade Federal de São Paulo, São Paulo, Brazil
}

\begin{abstract}
The hemolytic uremic syndrome (HUS) caused by Shiga toxin-producing Escherichia coli (STEC) is one of the most frequent causes of pediatric acute renal failure. The aim of this study was to report the clinic and microbiologic features associated with 13 post-diarrheal HUS cases identified in pediatric intensive care units in the city of São Paulo, Brazil, from January 2001 to August 2005. Epidemiologic, clinic, and laboratorial information, along with fecal and serum samples, were collected for identifying the genetic sequences of Stx and for studying antibodies directed against LPS O26, O111 and O157. STEC was isolated from three patients, and serotypes O26:H11, O157:H7 and O165: $\mathrm{H}^{-}$were identified. In nine patients, high levels of IgM against LPS O111 ( $\mathrm{n}=2)$ and O157 ( $\mathrm{n}=7)$ were detected. Dialysis was required in $76.9 \%$ of the patients; arterial hypertension was present in $61.5 \%$, neurological complications were observed in $30.7 \%$, and only one patient died. During a 5-year follow-up period, one patient developed chronic kidney disease. The combined use of microbiologic and serologic techniques provided evidence of STEC infection in $92.3 \%$ of the HUS cases studied, and the importance of O157 STEC as agents of HUS in São Paulo has not been previously highlighted.
\end{abstract}

Keywords: Hemolytic Uremic Syndrome, pediatric intensive care unit, diarrhea, Shiga toxin, E. coli O157, dialysis, children.

\section{INTRODUCTION}

Hemolytic Uremic Syndrome (HUS), a life-threatening human illness, has been associated with Shiga toxinproducing Escherichia coli (STEC) infections, particularly in children [1]. Although serotype O157:H7 was the first to be associated with enterohemorrhagic disease and represent most of the STEC strains related to large outbreaks and severe disease, a number of other non-O157 serotypes has been equally associated with the occurrence of HUS [2]. Production of Shiga toxins $\left(\mathrm{Stx}_{1}\right.$ and $\left.\mathrm{Stx}_{2}\right)$ is a key step in the virulence mechanism of STEC, believed to be the most important event towards HUS development [3]. However, presence of other virulence factors like a hemolysin called enterohemorrhagic E. coli (EHEC) hemolysin (Ehx) and the intimin protein, present in strains that harbor the eae gene, can also contribute to STEC pathogenesis [4]. Infections due to STEC have a proven zoonotic character, being ruminant animals, especially cattle, the most important natural reservoir [5]. Therefore, transmission of STEC to humans occurred mainly via the food chain or by direct contact with the animals or their environment, but person-to-person transmission, although less common, has also been reported $[6,7]$.

In Brazil, efforts have been made to establish a national surveillance system for HUS but there are still little or no

*Address correspondence to this author at the Rua Botucatu, $862,3^{\circ}$ andar, São Paulo - S. P.- Brazil; CEP: 04023-062; Tel: 5511 50832980;

E-mail: bec.guth@unifesp.br data available. However, in other Latin America countries as Argentina, HUS is the main cause of acute kidney disease and the second most predominant cause of chronic kidney disease in children under the age of five years, and responsible for more than $15 \%$ of kidney transplants in children and adolescents [8].

In 2001, we started a surveillance study on post-diarrheal HUS in São Paulo city, Brazil, to investigate the association of this syndrome with STEC infections. This study describes the results of the microbiologic and serologic investigation of cases admitted in pediatric intensive care units (PICU), and their evolution, prognosis and mortality.

\section{MATERIALS AND METHODS}

This was a prospective clinical, observational, multicenter, non-controlled and non-randomized study, performed from 2001 to 2005. The required information was disclosed by the Department of Intensive Care and the Pediatric Society in São Paulo, and pediatric intensive care physicians and nephrologists were asked to communicate the cases admitted to their units. The study was approved by the Research Ethics Committee at the Universidade Federal de São Paulo (UNIFESP), and parents gave informed consent for their children to be included in the study. The criteria for enrollment included children hospitalized in the PICU with an acute case of hemolytic microangiopathic anemia, kidney failure and thrombocytopenia, which was preceded by diarrhea with or without blood. HUS was defined as acute 
anemia with hemoglobin $<10.5 \mathrm{~g} / \mathrm{dl}$, with or without evidence of erythrocyte fragmentation; thrombocytopenia with $<75,000 / \mathrm{mm}^{3}$; and acute kidney failure with creatinine levels over the upper limit for the age.

Personal and demographic data, as well as information regarding onset and type of diarrhea, previous use of antibiotics, cases of diarrhea in the family or closely related people, eating habits, ingestion of undercooked meat or of nonpasteurized foods and contact with animals were collected. Clinical and laboratory monitoring was performed during the hospitalization from 2001 to 2005. Information about the long-term effects of the disease was obtained through contact with the parents and/or nephrologists who accompanied the patients. Data were collected until 2007.

\section{Isolation and Identification of STEC}

Fecal samples were collected as soon as HUS was suspected and plated onto Sorbitol-MacConkey agar and incubated at $37^{\circ} \mathrm{C}$ for 18 hours. Sorbitol fermenting and non-fermenting $E$. coli isolates were tested for $s t x_{1}$ and $s t x_{2}$ by polymerase chain reactions (PCR) [9]. The stx positive isolates were serotyped by standard procedures using $\mathrm{O}(\mathrm{O} 1$ - O181) and $\mathrm{H}$ (H1-H56) antisera kindly provided by the Centers for Diseases Control and Prevention (CDC, USA) [10]. STEC isolates were further tested for the presence of intimin (eae) and enterohemolysin (ehx A) gene sequences by PCR as previously described $[11,12]$. To verify the expression of Stx toxins, filtrates from $E$. coli positive culture samples used in the PCR trials were prepared and inoculated into HeLa and Vero cell monolayers, [13].

\section{Detection of LPS Antibodies}

Presence of IgM and IgG classes of antibody against LPS O26, O111 and O157 was searched for by enzyme-linked immunosorbent (ELISA) assays in serum samples collected from all patients except one, at admission or as soon as HUS was diagnosed (acute phase) using the methods described $[14,15]$. In brief, PolySorp ELISA plates (NUNC, Naperville, III., USA) were coated with $10 \mu \mathrm{g} / \mathrm{ml}$ of $E$. coli LPS O26 and O111, purchased from Sigma (Sigma Chemical Co. - St. Louis, MO, USA), and LPS O157 (List Biological Laboratories, Inc - California, USA). Sera samples were diluted 1:500 in Phosphate-buffered saline (PBS) containing 0.05\% Tween 20 and incubated for 2 hours at room temperature. Presence of $\operatorname{IgM}$ and $\operatorname{IgG}$ antibodies was investigated in the samples by using anti-human IgM and IgG conjugated peroxidase (Sigma) diluted 1:1000 and incubated for 2 hours at room temperature. Reaction was developed with $10 \mathrm{mg}$ of ophenylenediamine in citrate buffer $\mathrm{pH} 4.5$ containing $0.012 \%$ $\mathrm{H}_{2} \mathrm{O}_{2}$, and absorbance values were measured at $492 \mathrm{~nm}$ $\left(\mathrm{A}_{492}\right)$. Positive sera controls were included in all ELISA assays and were obtained from patients who had HUS in association with STEC O26 and O157 infections (kind gift from Dr. Alfredo Caprioli, Istituto Superiore di Sanità, Rome, Italy). The O111 positive control serum was obtained at the beginning of this study.

One sera sample obtained from 63 children without gastrointestinal symptoms and infection who had visited the outpatient clinic of the São Paulo Hospital from August to September of 2004 were used to evaluate the presence of antibodies against LPS O26, O111 and O157 in the general population. All sera were diluted 1:500 in PBS-Tween, and the cutoff value was defined as the average of the IgM or IgG values in the sera plus three times the value of the standard deviation.

To confirm the specifity of the ELISA results, LPS immunoblotting was performed as described by Chart et al. [16] using patients sera diluted 1:100, and bound immunoglobulin was detected using anti-human polyvalent immunoglobulins conjugated peroxidase (Sigma Chemical Co.) diluted 1:2000 and the reaction was developed using chemiluminescent detection system (ECL, Amersham Biosciences, Sweden).

\section{RESULTS}

\section{Epidemiology}

Thirteen cases fulfilled the diagnostic criteria and there was no refusal to participate in the study. Ten patients $(77 \%)$ came from private hospitals and three (23\%) from public hospitals. Ages ranged from 8 months to 6 years and 3 months, with a mean of 2 years and 5 months. However, almost half of the patients $(46 \%)$ were less than 2 years old. Eight patients $(61.5 \%)$ were female. The seasonal distribution of the cases was as follows: six cases in the Summer, three in the Winter, three in the Spring and one in the Fall. All children had diarrhea, $69.2 \%$ with blood or mucus, and with diarrheal prodroms for a median of 6.4 days (Table 1 ). There were no reports of diarrhea or gastroenteritis among family members or people in close contact with the patients. A positive response to the ingestion of undercooked or nonpasteurized food, or contact with animals (specifically bovines) occurred in $69.2 \%$ of patients (Table $\mathbf{1}$ ).

\section{Isolation and Identification of STEC}

STEC was isolated from three out of seven patients whose stool cultures yielded bacterial growth, and serotypes O26:H11, O157:H7 and O165:HNM were identified (Table 1). Except for the $026: H 11$ strain that harbored stx 1 eae $e h x \mathrm{~A}$, the other STEC isolates presented the stx2 stx2c eae ehxA genotype. Expression of Stx was identified in all STEC isolates.

\section{LPS Antibodies}

Low levels of antibodies to LPS O26, O111 and O157 were identified in sera of children with no gastrointestinal disorders (control population), with cutoff values $(\mathrm{Cv}) \leq 0.5$, except for $\mathrm{O} 111 \mathrm{IgG}$ responses that presented variations, generating a $\mathrm{Cv}=1.095$ (Table 2, Fig. 1-3). In contrast, higher levels of O111 LPS antibodies (IgM and $\mathrm{IgG}$ ) were identified in sera of 2 out of 12 HUS patients (Table 1, Fig. 2), and increased levels of IgM to LPS O157 were detected in sera from 7 patients (Table 1, Fig. 3). In five of these seven patients, high levels of IgG were also identified. These levels of antibodies were much higher than the cuttoff values observed in the group of children with no diarrhea (Table 2, Figs. 2,3), even when higher serum dilutions (1:1000) were analyzed (data not shown). ELISA results were confirmed by specific O157 and O111 LPS recognition in HUS patient's sera by immunoblotting analysis (Fig. 4). Serum samples taken approximately 15 days after hospital admission (convalescence) were available for ELISA analysis from 7 of the 
Table 1. Epidemiologic, Microbiologic and Serologic Characteristics of HUS Patients

\begin{tabular}{|c|c|c|c|c|c|c|c|c|c|c|}
\hline Case & Season & $\operatorname{Sex}^{\mathrm{a}}$ & Age & Prodromes & $\begin{array}{l}\text { Bloody } \\
\text { Diarrhea }\end{array}$ & $\begin{array}{l}\text { Source of } \\
\text { Contamination }^{b}\end{array}$ & $\begin{array}{l}\text { STEC } \\
\text { Isolation }\end{array}$ & $\alpha-\mathbf{L P S}$ & \multicolumn{2}{|c|}{$\alpha-\operatorname{LPS}^{\mathrm{c}, \mathrm{d}}$} \\
\hline 1 & Summer & $\mathrm{F}$ & $3 \mathrm{y} 2 \mathrm{~m}$ & 3 days & - & NI & - & $\mathrm{O} 111$ & 0.58 & 1.70 \\
\hline 2 & Summer & M & $8 \mathrm{~m}$ & 21 days & + & Meat or milk & O26:H11 & - & - & - \\
\hline 3 & Spring & M & $8 \mathrm{~m}$ & 12 days & + & NI & - & - & - & - \\
\hline 5 & Summer & $\mathrm{F}$ & $2 \mathrm{y} 6 \mathrm{~m}$ & 5 days & + & Contact with cattle & - & $\mathrm{O} 157$ & 0.978 & 1.039 \\
\hline 6 & Winter & $\mathrm{F}$ & $1 \mathrm{y} 5 \mathrm{~m}$ & 8 days & + & Meat or milk & - & $\mathrm{O} 157$ & 2.90 & 0.82 \\
\hline 7 & Spring & $\mathrm{F}$ & $6 y 3 \mathrm{~m}$ & 5 days & + & $\mathrm{NI}$ & - & $\mathrm{O} 157$ & 1.00 & 0.116 \\
\hline 8 & Spring & M & $4 y 4 m$ & 7 days & - & Goat milk & - & $\mathrm{O} 157$ & 3.31 & 1.50 \\
\hline 11 & Summer & $\mathrm{F}$ & $1 \mathrm{y} 7 \mathrm{~m}$ & 3 days & - & Cheese & O165:H- & - & - & - \\
\hline 12 & Summer & M & $1 \mathrm{y} 7 \mathrm{~m}$ & 2 days & + & Meat or milk & - & O157 & 0.462 & 0.789 \\
\hline 13 & Winter & $\mathrm{F}$ & $3 y 10 \mathrm{~m}$ & 5 days & + & Contact with cattle & O157:H7 & NT & NT & NT \\
\hline
\end{tabular}

${ }^{\mathrm{a}} \mathrm{F}$, female; $\mathrm{M}$, male

${ }^{\mathrm{b}} \mathrm{NI}$, not identified

${ }^{\mathrm{c}}$ ELISA absorbance values measured at $492 \mathrm{~nm}$; NT, not tested; all sera were diluted 1:500 in PBS-Tween.

${ }^{\mathrm{d}}$ Abs values for positive 1:500 diluted sera controls $\alpha$-LPS O26: IgM 1.6; IgG 2.1; $\alpha$-LPS O111: IgM 0.58; IgG 1.7; $\alpha$-LPS O157: IgM 2.2; IgG 1.6.

Table 2. Investigation of Antibodies against LPS O26, O111 and 0157 in 1:500 Diluted Sera of the Control Child ren by ELISA

\begin{tabular}{|c|c|c|c|c|c|c|}
\hline \multirow{2}{*}{ Control children (n=63) } & \multicolumn{2}{|c|}{ Antibody LPS O26 ${ }^{\text {a }}$} & \multicolumn{2}{|c|}{ Antibody LPS O111 $^{\text {a }}$} & \multicolumn{2}{|c|}{ Antibody LPS O157 $^{\text {a }}$} \\
\cline { 2 - 6 } & IgM & IgG & IgM & IgG & IgM & 0.068 \\
\hline \hline IgG & 0.104 & 0.279 & 0.079 \\
\hline Standard Deviation (SD) & 0.057 & 0.086 & 0.102 & 0.272 & 0.084 & 0.102 \\
\hline Cutoff value (Cv=M+3xSD) & 0.318 & 0.341 & 0.410 & 1.095 & 0.320 \\
\hline
\end{tabular}

${ }^{a}$ Values are expressed as absorbance at $492 \mathrm{~nm}$ and were calculated using the GraphPad Prism 4.0 program.

9 HUS patients that presented O111 $(n=1)$ or O157 $(n=6)$ LPS antibodies response. All these sera presented a decreased in IgM levels compared to the acute phase sera, but in five patients the $\operatorname{IgM}$ and $\mathrm{IgG}$ levels were still higher than the cuttoff values (data not shown).

\section{Clinical and Laboratory Data}

The clinical and laboratory characteristics of HUS cases are shown in Table 3. The average hemoglobin value was 8.2 $\mathrm{g} / \mathrm{dl}$, and the lowest limit for platelets was $15,000 / \mathrm{mm}^{3}$. Changes in kidney function showed average creatinine values of $3.27 \mathrm{mg} / \mathrm{dl}$, and average urea values of $132 \mathrm{mg} / \mathrm{dl}$. Four patients $(30 \%)$ showed the presence of schistocytes. Normalization of the platelet count occurred in $76 \%$ of the patients two weeks after the onset of the disease. Only $38 \%$ of the patients exhibited normalization of creatinine levels in the first two weeks of the disease, and two patients $(15 \%)$ exhibited oliguria for a period of more than 15 days. Arterial hypertension was observed in eight patients (61.5\%), and involvement of the central nervous system was seen in four $(30.7 \%)$; changes in other organs or systems were not observed. Renal replacement therapy with peritoneal dialysis in the first 24 hours of admission to the PICU was necessary in $10(76.9 \%)$ patients, with an average time of dialysis of 12 days (range: 6-38 days). The average length of stay in PICU was 16 days, and the average duration of hospitalization was 24 days. The only patient who died exhibited severe arterial hypertension that was difficult to control, bleeding and neurological involvement; anti-LPS O111, IgM (0.775) and IgG (3.200) antibodies were also detected. During the 2 to 5 years following hospitalization, a questionnaire was sent to the parents or nephrologists who had accompanied the children. From this, we found that only one patient (1/10) had developed chronic kidney disease without hypertension or the need for dialysis after discharge, but had persistent proteinuria. Two patients presented neurological sequelae, one of them with paresis of the lower left limb from a hemorrhagic 


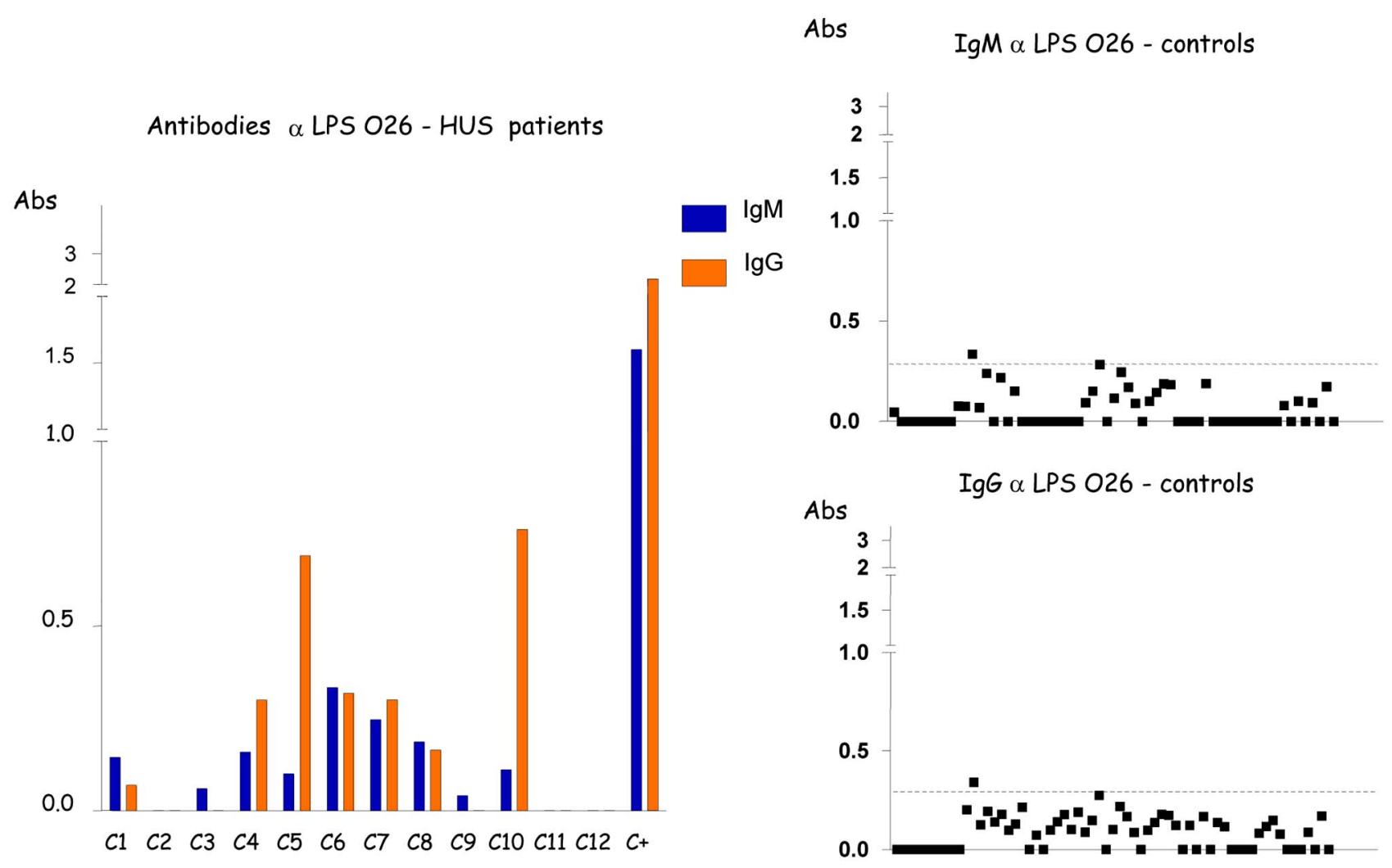

Fig. (1). Detection of IgM and IgG antibodies against LPS O26 in the serum from patients with HUS and controls by ELISA. Serum samples were diluted 1:500 in PBS-Tween, and absorbance values (Abs) were measured at $492 \mathrm{~nm}$.

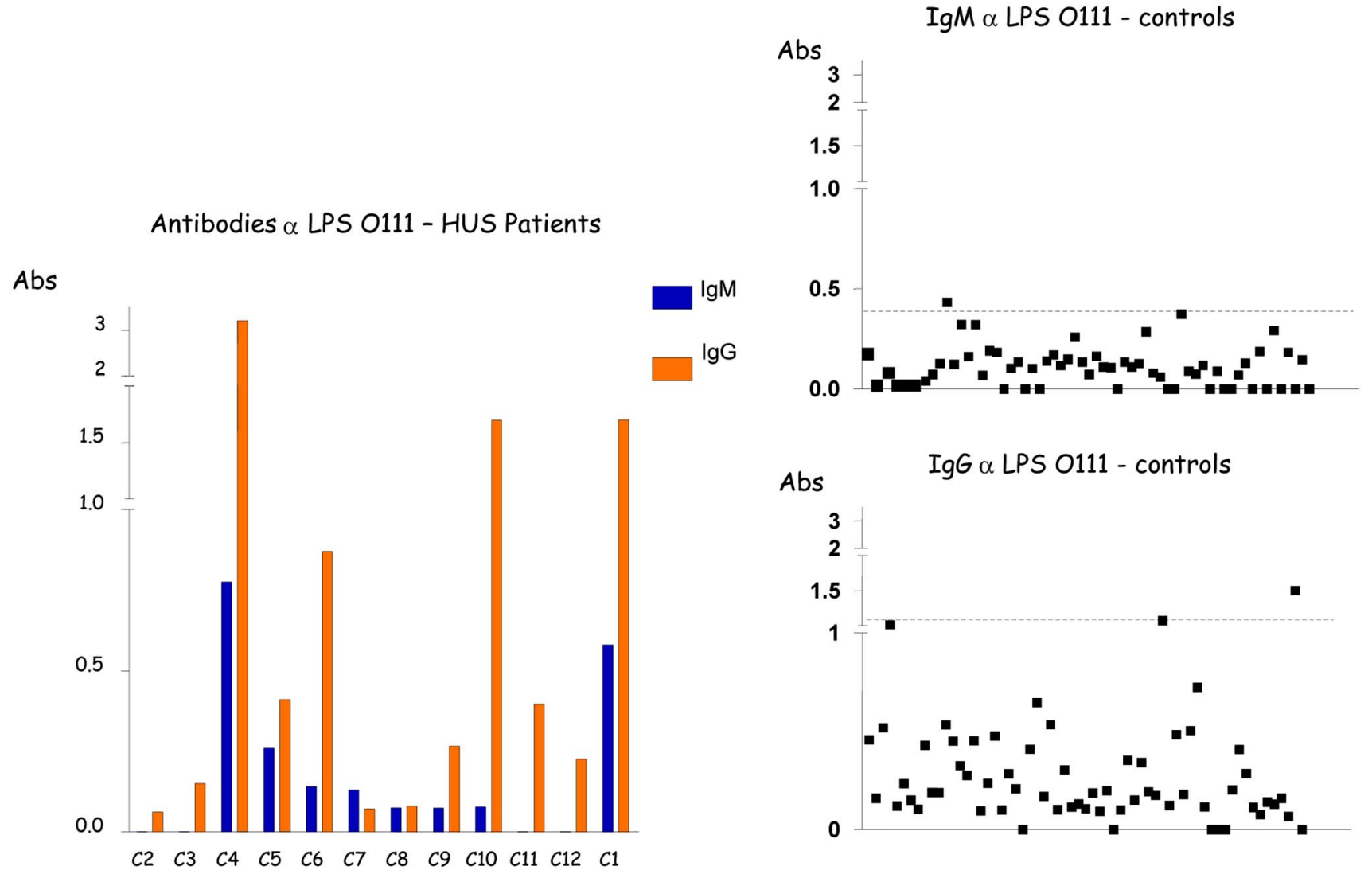

Fig. (2). Detection of. IgM and IgG antibodies against LPS O111 in the serum from patients with HUS and controls by ELISA. Serum samples were diluted 1:500 in PBS-Tween, and absorbance values (Abs) were measured at $492 \mathrm{~nm}$. 


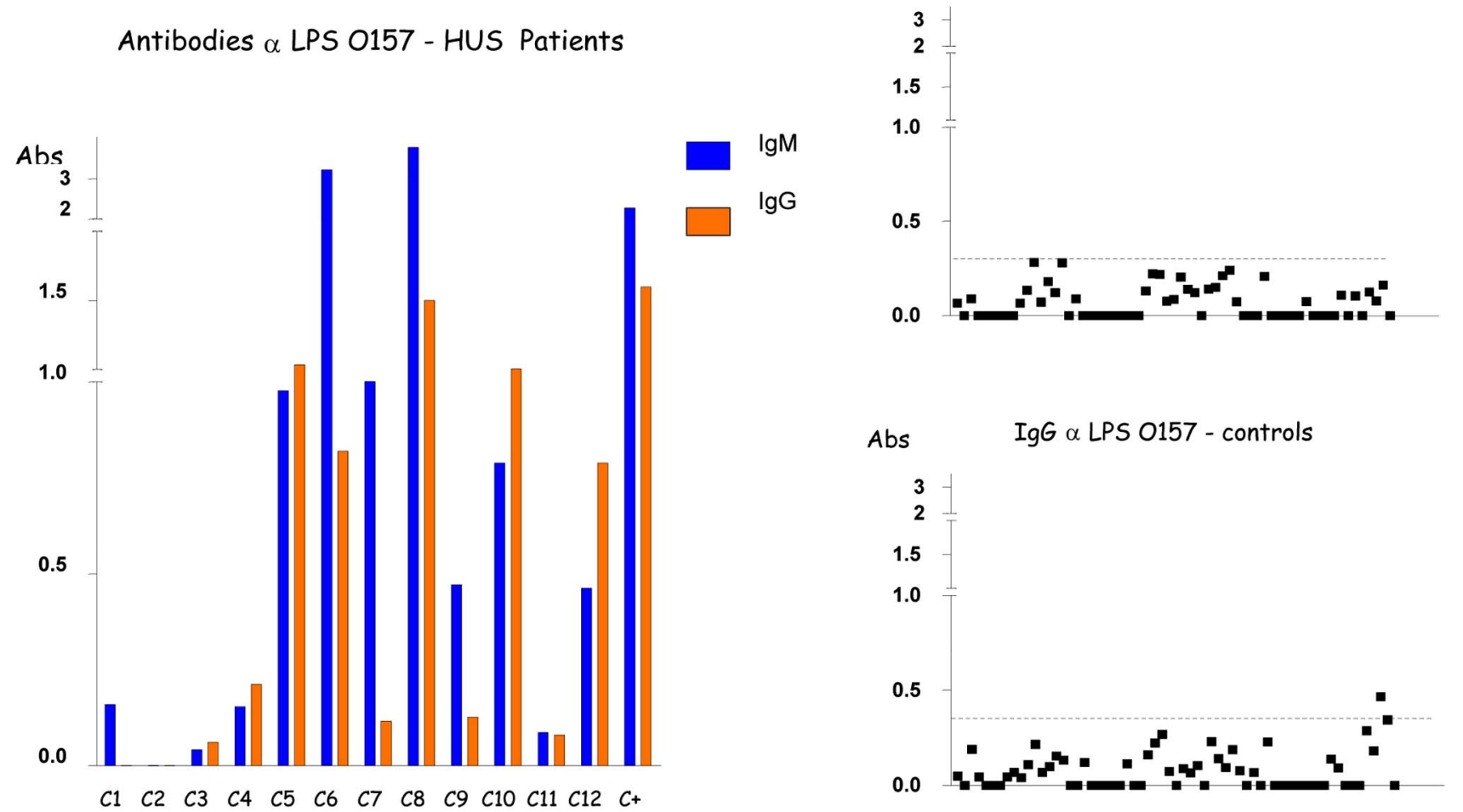

Fig. (3). Detection of IgM and IgG antibodies against LPS O157 in the serum from patients with HUS and controls by ELISA. Serum samples were diluted 1:500 in PBS-Tween, and absorbance values (Abs) were measured at $492 \mathrm{~nm}$.

stroke during hospitalization. The other exhibited differences in walking due to unknown causes, four years after being discharged from the hospital.

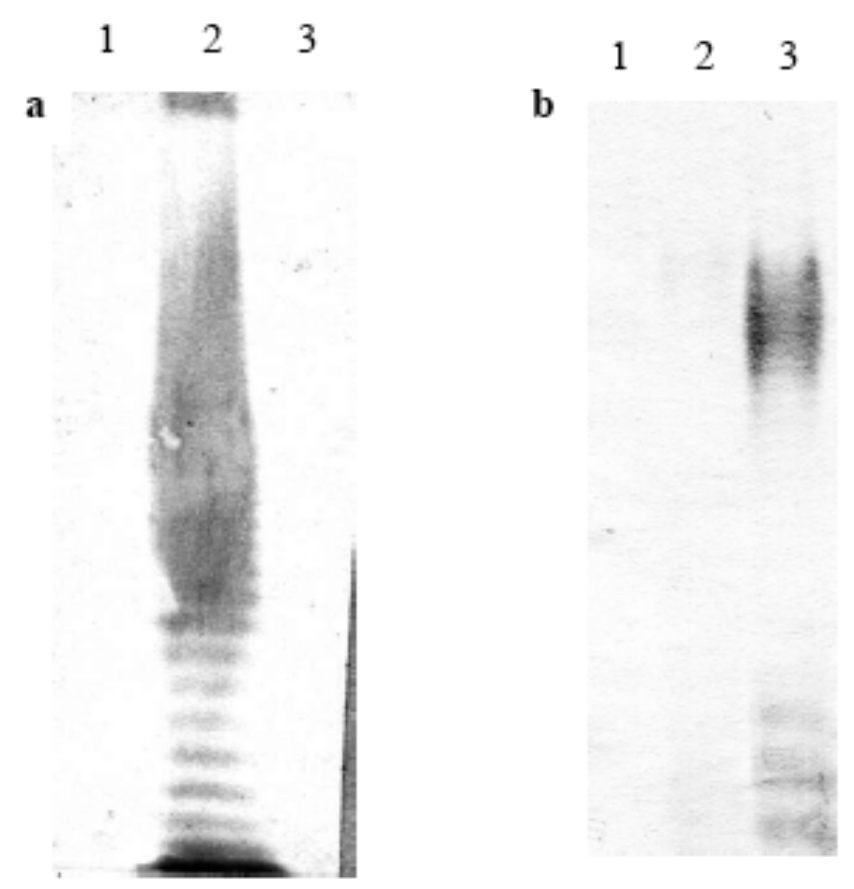

Fig. (4). Representative reaction of patients sera with 0111 and O157 LPS by immunoblotting. a, serum of patient positive for LPS O111 ( case 1 ); b, serum of patient positive for LPS O157 (case 8). Lanes: 1, LPS O26; 2, LPS O111; 3, LPS O157.
Table 3. Clinic and Laboratory Characteristics of Patients with HUS

\begin{tabular}{|l|l|}
\hline Characteristics & Total Case Data and Values \\
\hline \hline Clinical & \\
Diarrhea w/ blood & 9 patients $(69.2 \%)$ \\
Dialysis & 10 patients $(76.9 \%)$ \\
Duration of dialysis & 12 days $(6-38$ days) \\
Hypertension & 8 patients $(61.5 \%)$ \\
Neurological symptoms & 4 patients $(30.7 \%)$ \\
Time of ICU hospitalization & 16 days $(5-68$ days) \\
Time of hospitalization & 24 days $(7-73$ days) \\
Chronic kidney disease & $1 / 10$ patients $(10 \%)$ \\
\hline Laboratory results & \\
Hb (g/dl) & $4.7-10.5^{\mathrm{a}}$ \\
Platelets per mm & $15,000-75,000^{\mathrm{a}}$ \\
Creatinine (mg/dl) & $1.1-6.6^{\mathrm{b}}$ \\
Hematuria & 5 patients $(38.5 \%)$ \\
\hline
\end{tabular}

${ }^{a}$ represent the range values of lower limits among patients

${ }^{b}$ represent the range values of upper limits among patients

\section{DISCUSSION}

The first report of a case of HUS in Brazil was made by Penna et al. in 1967 [17]. In 1983, Carvalhaes and Nobrega described two cases of post-diarrheal HUS in five-month-old twins [18]. 
The incidence of HUS in São Paulo is not well documented and diagnosis may also be underestimated. Data from the center for epidemiological surveillance in the State of São Paulo (www.cve.saude.sp.gov.br/htm/hidrica/hidri estat.html) show an incidence of HUS from 1998 to $200 \overline{7}$ that ranges from 0.01 to 0.05 per 100,000 children, but all forms of HUS are included. During the period of this study, we identified 13 HUS cases associated with diarrhea, and all the cases exhibited the characteristics of the illness and therefore fit the classic definition of HUS.

In Argentina, HUS incidence increased from 8.2, in 1998 , to $13.9 / 100,000$ children under five years of age in 2005. This was due, in part, to the mandatory notification by the national epidemiological surveillance system, established in 2000 by the ministry of health [8]. In Germany and Austria, the incidence is 0.7 and 0.4 , respectively, in children younger than 15 years of age [19]. In France, the incidence is 0.7 in children younger than 15 and 1.8 per 100,000 children younger than 5 years [20]. In England, the incidence is 1.54 in children younger than five, while it is 3.4 in Scotland and 2.33 in Ireland [21]. In Italy, the incidence is 0.2 [22], and the reported incidence ranges from 0.2 to 3.4 in the USA [6].

Albeit the paucity of data on HUS associated STEC infections in our settings, several STEC serotypes, including those principals responsible for HUS in other countries, have been isolated from sporadic cases of diarrhea, particularly in children, in different regions of Brazil [23-31]. Maybe the most important factor is the lack of warning before onset of the illness, but physicians should be watchful for cases of severe diarrhea, especially in young infants, since $15 \%$ of STEC infections can develop into HUS [32], and $90 \%$ of HUS cases are caused by STEC [7, 33].

Our study was the first to successfully demonstrate the isolation and identification of $\mathrm{O} 157: \mathrm{H} 7$ as well as non-O157 STEC strains in patients with HUS in Brazil. The first HUS case associated with STEC O26:H11 was reported in 2002, and the other related to STEC O165:H- was published in $2007[34,35]$.

The detection of serum antibodies to the LPS of E. coli O157 and other non-O157 isolates has been reported as an effective method to diagnose infections by these organisms in HUS patients $[14,16,33,36]$. In the present study, high levels of antibodies to O157 LPS were detected in sera of seven patients. These results strongly support evidence of infection by $\mathrm{O} 157$ isolates in these HUS patients, as prevalence of LPS antibodies in the control population was very low. On the other hand, a more caution analysis on the association of O111 LPS response and HUS needs to be made. This serogroup can be related to different diarrheagenic $E$. coli pathotypes, and has been frequently implicated as agents of children diarrhea in São Paulo, Brazil [26, 37]. The high titers of IgG to O111 LPS presently identified among the control population, and in some HUS patients, certainly reflect the important circulation of this serogroup in our settings. However, the higher titers of IgM antibodies to LPS O111 identified in two HUS patients, compared to the cutoff values obtained among the controls, can suggest an evidence of association of this serogroup with the present disease. In addition, the specificity of the ELISA results was also confirmed by immunoblotting analysis, that showed specific O157 and O111 LPS recognition in HUS patients sera. The above results confirm that investigation of the specific immune response can improve the diagnosis of STEC infections especially in HUS patients whose stool cultures are negative $[14,16,33]$.

Although in the present study the source of infection was not traced back, the reported consumption of non-pasteurized milk or undercooked meat seemed to be the primary cause of infection in the majority of the cases studied, as reported by others $[6,8,38,39]$.

The data presented on the evolution of the illness, dialysis, prognosis, and mortality are similar to those described in the literature $[8,19,20]$. Dialysis started during admission when the patient presented with oliguria or anuria. The percentage of patients on dialysis in Germany, Austria and Australia $(63 \%)$ was closer to our study and greater than that from Argentina (59.8\%), France (53\%) and the USA (55\%). Our population consisted of patients admitted in the PICU, thus the severity of the conditions may justify the greater requirement of dialysis (77\%) and the development of arterial hypertension $(61.5 \%)$. However, in the study by Gerber et al. [19], only $15 \%$ exhibited elevation of blood pressure levels.

In spite of the low mortality, renal sequelae and chronic kidney disease can reach $50 \%$ in the long term if all forms of HUS are considered. Miliwebsky et al. [40] analyzed cases of HUS associated with STEC infections, and reported recovery of renal function in $96.2 \%$ of the patients and chronic kidney disease in only $2.4 \%$, while Cavagnaro et al. [41] reported that $11.6 \%$ of the patients developed chronic kidney disease. Complete recovery of renal function within the first months after the illness was exhibited by the majority of our patients. Certainly, the prognosis of typical HUS is better, and recurrence is rare when compared with other forms of the syndrome [32]. The monitoring time for our patients was relatively short, and it seems prudent to evaluate renal function and proteinuria/hematuria for several years after HUS. Neurological changes were found in four patients. One of them died, and the other two exhibited sequelae, one with delayed changes in walking. In studies on the prognosis of HUS, data are not presented in relation to neurological sequelae or concern over neuro-motor complications. It seems important that pediatricians remain vigilant over the changes in neurological development in patients affected by HUS.

In conclusion, the combined use of microbiologic and serologic techniques provided evidence of STEC infection in 92.3\% of the HUS cases studied, and the importance of O157 STEC as agents of HUS in São Paulo has not been previously highlighted. Albeit the limited number of HUS cases identified during the studied period, that may fortunately suggest a relatively low incidence of this syndrome, our data strongly indicate that in order to accurately diagnose HUS and identify the etiological agent, implements of a surveillance system based on information from nephrologists, intensive care specialists and general pediatricians as well as on proper laboratory diagnostic procedures are needed.

\section{ACKNOWLEDGEMENTS}

We thank all parents of children for their kind cooperation during the interviews, and all the pediatric intensive care physicians for collaboration during the studied period. This 
work was supported by grants from Fundação de Amparo à Pesquisa do Estado de São Paulo (FAPESP) n 01/07921-7, and Conselho Nacional de Desenvolvimento Científico e Tecnológico, CNPq, Brasília, Brazil.

\section{REFERENCES}

[1] Karmali MA. Infection by verocytotoxin-producing Escherichia coli. Clin Microbiol Rev 1989; 2: 15-38.

[2] Paton JC, Paton AW. Pathogenesis and diagnosis of Shiga toxinproducing Escherichia coli infections. Clin Microbiol Rev 1998; 11: 450-70.

[3] Karmali, MA, Petric M, Lim C, Fleming PC, Steele BT. Escherichia coli cytotoxin, hemolytic-uremic syndrome, and haemorrhagic colitis. Lancet 1983; ii: 1299-300.

[4] Kaper JB, Nataro JP, Mobley HLT. Pathogenic Escherichia coli. Nat Rev 2004; 2: 123-40.

[5] Caprioli A, Morabito S, Brugere H, Oswald E. Enterohemorrhagic Escherichia coli: emerging issues on virulence and modes of transmission. Vet Res 2005; 36: 289-311.

[6] Verweyen HM, Karch H, Brandis M, Zimmerhackl LB. Enterohemorrhagic Escherichia coli infections : following transmission routes. Pediatr Nephrol 2000; 14: 73-83.

[7] Repetto,HA. Epidemic hemolytic-uremic syndrome in children. Nephrology Forum. Kidney Int 1997; 52: 1708-19.

[8] Rivas M, Milwebsky E, Chinen I, Deza N, Leotta G. The epidemiology of hemolytic uremic syndrome in Argentina: diagnosis of the etiologic agent, reservoirs and routes of transmission. Medicina (B. Aires) 2006; 66: 27-32.

[9] Pollard DR, Johnson WM, Lior H, Tyler SD, Rozee KR. Rapid and specific detection of verotoxin genes in Escherichia coli by the polymerase chain reaction. J Clin Microbiol 1990; 28: 540-5.

[10] Ewing WH. Edwards \& Ewing's identification of Enterobacteriaceae. $4^{\text {th }}$ Ed Elsevier Science Publishers: New York 1986.

[11] Karch H, Schubert S, Zhang D, et al. A genomic island, termed high -pathogenicity island, is present in certain non-O157 Shiga toxin-producing Escherichia coli clonal lineages. Infect Immun 1999; 67: 5994-6001.

[12] Schmidt H, Beutin L, Karch H. Molecular analysis of the plasmidencoded hemolysin of Escherichia coli O157:H7 strain EDL 933. Infect Immun 1995; 63: 1055-61.

[13] Gentry MK, Dalrymple JM. Quantitative microtiter cytotoxicity assay for Shigella toxin. J Clin Microbiol 1980; 12: 361-6.

[14] Caprioli A, Luzzi I, Rosmini F, et al. Hus Italian Study Group. Hemolytic-Uremic Syndrome and Vero cytotoxin-producing Escherichia coli infection in Italy. J Infect Dis 1992; 166: 154-8.

[15] Tsutsumi R, Ichinohe N, Shimooki O, et al. Homologous and heterologous antibody responses to lipopolysaccharide after enterohemorrhagic Escherichia coli infection. Microbiol Immunol 2004; 48: 27-38.

[16] Chart H, Smith HR, Scotland SM, Rowe B, Milford DV, Taylor CM. Serological identification of Escherichia coli O157:H7 infection in haemolytic uraemic syndrome. Lancet 1991; 337: 138-40.

[17] Penna HAO, Manissadjian A, Okay Y. Síndrome HemolíticoUrêmica (Microangiopatia Trombótica) - Apresentação de um Caso. Rev Hosp Clin Fac Med S Paulo 1967; 22: 295-302.

[18] Carvalhaes JTA, Nóbrega FJ. Síndrome hemolítica urêmica (SHU) em gêmeos lactentes. Rev Paulista Pediatr 1983; 1: 18-22.

[19] Gerber A, Karch H, Allerberger F, Verweyen HM, Zimmerhackl LB. Clinical course and the role of Shiga toxin-producing Escherichia coli infection in the hemolytic-uremic syndrome in pediatric patients, 1997-2000, in Germany and Austria: a prospective study. J Infect Dis 2002; 186: 493-500.

[20] Decludt B, Bouvet P, Mariani-Kurkdjian P, et al. Haemolytic uraemic syndrome and Shiga toxin-producing Escherichia coli infection in children in France. Epidemiol Infect 2000; 124: 215-20.
[21] Lynn RM, O'Brien SJ, Taylor CM, et al. Childhood hemolytic uremic syndrome, United Kingdom and Ireland. Emerg Infect Dis $2005 ; 11: 590-6$.

[22] Tozzi AE, Caprioli A, Minelli F, et al. Hemolytic uremic syndrome study group. Emerg Infect Dis 2003; 9: 106-8.

[23] Cantarelli V, Nagayama K, Takahashi A, et al. Isolation of Shiga toxin-producing Escherichia coli (STEC) serotype O91:H21 from a child with diarrhea in Porto Alegre city, RS, Brazil. Braz J Microbiol 2000; 31: 266-70.

[24] Guth BEC, Ramos SRTS, Cerqueira AMF, Andrade JRC, Gomes TAT. Phenotypic and genotypic characteristics of Shiga toxinproducing Escherichia coli strains isolated from children in São Paulo, Brazil. Mem Inst Oswaldo Cruz 2002; 97: 1085-9.

[25] Irino K, Vaz TMI, Kato MAMF, et al. O157:H7 Shiga toxinproducing Escherichia coli strains associated with sporadic cases of diarrhea in São Paulo, Brazil. Emerg Infect Dis 2002; 8: 446-7.

[26] Vaz TMI, Irino K, Kato MAMF, et al. Virulence properties and characteristics of Shiga toxin-producing Escherichia coli in São Paulo, Brazil, from 1976 trough 1999. J Clin Microbiol 2004; 42: 903-5.

[27] Guth BEC, Vaz TMI, Gomes TAT, et al. Re-emergence of O103:H2 Shiga toxin-producing Escherichia coli infections in São Paulo, Brazil. J Med Microbiol 2005; 54: 805-6.

[28] Orlandi PP, Magalhães GF, Matos NB, et al. Etiology of diarrheal infections in children of Porto Velho (Rondonia, Western Amazon region, Brazil). Braz J Med Biol Res 2006; 39: 507-17.

[29] Franzolin MR, Alves RCB, Keller R, et al. Prevalence of diarrheagenic Escherichia coli in children with diarrhea in Salvador, Bahia, Brazil. Mem Inst Oswaldo Cruz 2005; 100: 359-63.

[30] Irino K, Vaz TMI, Medeiros MIC, et al. Serotype diversity as a drawback in the surveillance of Shiga toxin-producing Escherichia coli infections in Brazil. J Med Microbiol 2007; 56: 565-7.

[31] De Toni F, Souza EM, Pedrosa FO, et al. A prospective study on Shiga toxin-producing Escherichia coli in children with diarrhoea in Paraná State, Brazil. Lett Appl Microbiol 2009; 48: 645-7.

[32] Tarr PI, Gordon CA, Chandler WL. Shiga-toxin-producing Escherichia coli and haemolytic uraemic syndrome. Lancet 2005; 365: 1073-86.

[33] Banatvala N, Griffin PM, Greene KD, et al. The United State national prospective hemolytic uremic syndrome study: microbiologic, srologic, clinical, and epidemiologic findings. J Infect Dis 2001; 183: 1063-70.

[34] Guth BEC, Souza RL, Vaz TMI, Irino K. First Shiga toxinproducing Escherichia coli isolated from a patient with hemolytic uremic syndrome, Brazil. Emerg Infect Dis 2002; 8: 535.

[35] Souza RL, Nishimura LS, Guth BEC. Uncommon Shiga toxinproducing Escherichia coli serotype O165:HNM as cause of hemolytic uremic syndrome in São Paulo, Brazil - Case Report. Diagn Microbiol Infect Dis 2007; 59: 223-5.

[36] Thomas A, Cheasty T, Frost JA, Chart H, Smith HR, Rowe B. Verocytoxin producing E. coli, particulary serogroup O157, associated with human infections in England and Wales: 1992-94. Epidemiol Infect 1996; 117: 1-10.

[37] Gomes TAT, Griffin PM, Ivey C, Trabulsi LR, Ramos SRTS EPEC Infections in São Paulo. Rev Microbiol 1996; 27: 25-33.

[38] Espié E, Vaillant V, Mariani-Kurkdjian P, et al. Escherichia coli O157 outbreak associated with fresh unpasteurized goats 'cheese. Epidemol Infect 2006; 134: 143-6.

[39] Perez N, Rahman R, Zalva J, Bibiloni N, Lasarte P, Spizirri F. HUS and unpasteurized milk. Acta Pediatr 1994; 83: 142.

[40] Miliwebsky ES, Balbi L, Gomez D, et al. Síndrome urémico hemolítico em niños de Argentina: asociación com la infección por Escherichia coli productor de toxina shiga. Bioquimica y Patologia Clinica 1999; 63: 113-21.

[41] Cavagnaro FSM, Gana JCA, Lagomarsino EF, Vogel AS, Gederlini AG. Síndrome hemolítico urémico. Experiência de um centro pediátrico. Rev Méd Chile 2005; 133: 781-7. 